\title{
Anti-Annexin A2 IgM Antibody in Preterm Infants: Its Association with Chorioamnionitis
}

\author{
FUMIHIKO NAMBA, HIROYUKI KITAJIMA, ATSUSHI TABATA, MASAHIRO NAKAYAMA, NORIYUKI SUEHARA, \\ KATSURA MATSUNAMI, KEIKO YANAGIHARA, MASAHIRO NISHIHARA, AKIHIRO MORITA, MINORU YAMADA, \\ AKIHITO KIMOTO, SHINYA HIRANO, KIYOTOSHI SEKIGUCHI, MASANORI FUJIMURA, AND ITARU YANAGIHARA \\ Departments of Developmental Infectious Diseases [F.N., A.T., M.Ni., A.M., M.Y., I.Y.], Neonatology [H.K., S.H., M.F.], Pathology and \\ Laboratory Medicine [M.Na., A.K.], Obstetrics [N.S.], Clinical Trials Office [K.M., K.Y., S.H.] Osaka Medical Center and Research \\ Institute for Maternal and Child Health, Osaka 594-1101, Japan; Division of Protein Chemistry [K.S.], Institute for Protein Research, \\ Osaka University, Osaka 565-0871, Japan
}

\begin{abstract}
Intrauterine infection is associated with chorioamnionitis (CAM), which can lead to preterm delivery. We previously reported that the levels of $\operatorname{IgM}$ and the incidence of CAM were elevated in preterm infants with neonatal pulmonary emphysema. The pathogen and target of this IgM remain unclear. By using Western blot and amino acid sequences, we have determined one of the target proteins: annexin A2. Immunohistochemical analysis showed that annexin A2 was expressed at fetal chorion and amnion membranes. Among very low birth weight (VLBW) infants with hyper- $\operatorname{IgM}(\geq 30 \mathrm{mg} / \mathrm{dL}), 58.8 \%$ showed a high titer against annexin A2 (more than $\times 16$ ), which accounted for about $20 \%-40 \%$ of the total IgM. Anti-annexin A2 IgM antibody inhibited plasmin generation. Furthermore, the median of anti-annexin A2 IgM titer from preterm infants who were delivered with high-grade (grade III) CAM was significantly higher than those from preterm infants without CAM $(p=0.011)$ and with low-grade CAM (grade I and II) $(p=$ 0.010 ). Here, we indicate the fetal autoimmunoreactivity against the fetomaternal interface in preterm infants. (Pediatr Res 60: 699-704, 2006)
\end{abstract}

O AM is a pathologic status of the placental membranes and is often interpreted as an intrauterine inflammatory response. CAM is present in $70 \%-80 \%$ of preterm births of $<30$ wk of gestational age $(1,2)$. It is reported that the pathogenesis of CAM is associated with microbial invasion of the amniotic cavity $(3,4)$ and that the level of inflammatory cytokines is elevated in the amniotic fluid and fetuses affected by CAM (5). These elevated cytokine levels are associated with an increased risk of bronchopulmonary dysplasia (BPD), periventricular leukomalacia, and necrotizing enterocolitis in preterm infants $(6,7)$. This status is called fetal inflammatory response syndrome (FIRS) (8).

Despite developments in medical treatment, BPD is, to date, one of the most important disorders for the morbidity and

Received March 9, 2006; accepted August 8, 2006

Correspondence: Itaru Yanagihara, M.D., Ph.D., Osaka Medical Center and Research, Institute for Maternal and Child Health, Department of Developmental Infectious Diseases, 840 Murodo-cho, Izumi, Osaka 594-1101, Japan; e-mail: itaruy@mch. pref.osaka.jp

This work was supported by a grant from the Ministry of Health, Labor and Welfare, Japan; the Japan Health Sciences Foundation; Research on Child Health and Development, National Center for Child Health and Development, Japan; and the Foundation for Mother and Child Well-being, Osaka, Japan.

DOI: 10.1203/01.pdr.0000245910.10929.a6 mortality of preterm infants (9). Neonatal pulmonary emphysema is a severe type of BPD (10). We reported that this pulmonary emphysema syndrome was significantly associated with both CAM and elevated serum IgM levels $(11,12)$. However, the target molecule of this IgM remains unknown.

Annexins bind to negatively charged phospholipids in a calcium-dependent manner (13). Annexin A2 has been implicated in membrane attachment, endocytosis, and exocytosis, which are pivotal for various pathogens to interact with the host cells (14-20). On the other hand, annexin A2 also functions as a modulator in immunologic clearance and for procoagulant and anticoagulant remodeling factors in vascular damage: phagocytosis (19), bridging macrophage with secretory leukocyte protease inhibitor (14), von Willebrand factor secretion after histamine stimulation (20), and fibrin clot dissolution $(21,22)$. The protein promotes fibrinolysis on the apical surfaces of vascular endothelial cells by serving as a platform for the binding of plasminogen and tissueplasminogen activator (t-PA). This permits the efficient cleavage of plasminogen by t-PA for producing the fibrinolytic enzyme, plasmin (22). Overexpression of annexin A2 occurs in the leukocytes of a subset of patients having the hemorrhagic form of acute promyelotic leukemia (23). The production of anti-annexin A1 and A2 autoantibodies commonly occurs in lung cancer and is associated with high circulating levels of interleukin-6 (24). It has recently become clear that certain dysregulations in annexin expression and activity can be correlated with human diseases, which has led to the introduction of the term annexinopathies (25).

In this study, we investigated the target molecules of elevated $\operatorname{IgM}$ in preterm infants and found that one of the targets is a host cellular protein, annexin A2.

\section{METHODS}

Clinical features of hyper-IgM. Among 6086 infants admitted from 1981 to 2004, 2433 were VLBW infants (birth weight $<1500$ g) and 1966 cord bloods were analyzed for their IgM levels. Pathologic examinations were given to all placentas. Grading of CAM was determined according to Blanc's

Abbreviations: BPD, bronchopulmonary dysplasia; CAM, chorioamnionitis; RFU, relative fluorescent units; t-PA, tissue-plasminogen activator; VLBW, very low birth weight 
criteria (26). Acute and subacute CAM was classified according to the previous description (27).

Antigen preparation. All clinical specimens were taken after informed consent was obtained and approved by the Ethics Committee of Osaka Medical Center and Research Institute for Maternal and Child Health. Antigen preparation was performed to isolate plasma-membrane-enriched endothelial cell fraction by modification of the methods of Hajjar and Hamel (28). Briefly, umbilical arteries were prepared from a fresh normal umbilical cord with forceps and scissors. These were minced in phosphate-buffered saline containing $1 \mathrm{mmol} / \mathrm{L}$ ethylenediaminetetraacetic acid and $1 \mathrm{mmol} / \mathrm{L}$ phenylmethanesulfonylfluoride, and centrifuged at $3000 \times g$ at $4^{\circ} \mathrm{C}$ for $5 \mathrm{~min}$. The pellet was homogenized and recentrifuged at $3000 \times g$ at $4^{\circ} \mathrm{C}$ for $5 \mathrm{~min}$. Supernatants from these two centrifugations were mixed and centrifuged at $10,000 \times$ $g$ at $4^{\circ} \mathrm{C}$ for $30 \mathrm{~min}$. The supernatant was centrifuged at $100,000 \times g$ at $4^{\circ} \mathrm{C}$ for $1 \mathrm{~h}$, and the pellet was designated the 100-K membrane fraction and used in further analysis.

IgM target protein determination. The $100-\mathrm{K}$ membrane fraction was analyzed by Western blot. The transferred membrane was incubated with human sera from infants with hyper-IgM as a primary antibody and with horseradish peroxidase-conjugated anti-human IgM antibody (Sigma Chemical Co.-Aldrich, St. Louis, MO) as a secondary antibody. Next, 36-kD protein was digested with trypsin (Boehringer Mannheim, Indianapolis, IN). The trypsinized peptides were fractioned by micro high-performance liquid chromatography (HPLC). Automated Edman degradation of samples was performed using a protein sequencer (ABI 477A).

The 100-K membrane fraction was dissolved and the anti-annexin A2 mouse $\mathrm{F}(\mathrm{ab})^{\prime}{ }_{2}$ IgG antibody (BD Biosciences, San Jose, $\mathrm{CA}$ ) was added and incubated at $4^{\circ} \mathrm{C}$ overnight. Protein A/G PLUS Agarose SC-2003 (Santa Cruz Biotechnology, Santa Cruz, CA) was added to the lysate and incubated at $4{ }^{\circ} \mathrm{C}$ overnight. The immunocomplex was dissociated from the beads and analyzed by Western blot with sera of patients as a primary antibody.

Immunohistochemistry. After deparaffinization and hydration, the sections were soaked in $10 \mathrm{mmol} / \mathrm{L}$ sodium citrate buffer ( $\mathrm{pH} \mathrm{6.0)}$, and an antigen was retrieved. The slides were fixed in methanol containing $0.3 \%$ hydrogen peroxide, the sections were incubated with anti-annexin A2 antibody (BD Biosciences), and the immunoreactivity was detected with a Vector Elite ABC Kit (Vector Laboratories Inc., Burlingame, CA). Sections were counterstained with Mayer's hematoxylin.

Production of recombinant human annexin A2 and enzyme-linked immunosorbent assay (ELISA). We constructed an expression system for recombinant human annexin A2 by Pichia pastoris (29). The recombinant annexin A2 $(10 \mathrm{ng} / \mu \mathrm{L})$ was coated on a 96-well microtiter plate (Corning Inc., Corning, NY) and incubated at $4^{\circ} \mathrm{C}$ overnight. The serum of patients was serially diluted twofold and added into each well. The specific IgM against annexin A2 was detected with horseradish peroxidase-conjugated anti-human IgM antibody at room temperature for $1 \mathrm{~h}$ and colored with $o$ phenylenediamine (Sigma Chemical Co.-Aldrich).

Absorption of serum to recombinant annexin A2. To examine the proportion of anti-annexin A2 IgM antibody in total serum IgM, we measured the levels of IgM (Easy-Titer Human IgM Assay Kit, PIERCE, Rockford, IL) with or without absorption to recombinant annexin A2. Briefly, $50 \mu \mathrm{L}$ of diluted sera (1:100) from each of four anti-annexin A2 IgM high-titer patients and three normal adults were added into an annexin A2-coated plate (500 ng of recombinant annexin A2 per well) and incubated at $4^{\circ} \mathrm{C}$ overnight. The complete absorption of anti-annexin A2 IgM antibody to the plate was confirmed by ELISA. These sera were finally diluted at 1:1000, and $20 \mu \mathrm{L}$ of the sera were incubated with $20 \mu \mathrm{L}$ of anti-human IgM sensitized beads at room temperature for $5 \mathrm{~min}$ and the absorbance was measured at $405 \mathrm{~nm}$ by Microplate Reader, Model 3550 (Bio-Rad, Tokyo, Japan).

IgM purification and inhibition assay for plasmin generation. One hundred forty microliters of sera from each three anti-annexin A2 IgM high-titer patients and three normal adults were used to purify IgM. First, to remove $\mathrm{IgG}$, protein $\mathrm{A} / \mathrm{G}$ plus agarose $\mathrm{SC}-2003$ was used and then $\mathrm{IgM}$ was purified using an IgM purification kit (HiTrap IgM Purification Column; Amersham Pharmacia Biotech, Uppsala, Sweden) according to the manufacturer's instructions. The purity of IgM was confirmed by Western blot using anti-human IgM antibody (data not shown).

For the plasmin generation inhibition assay, the $100-\mathrm{K}$ membrane fraction containing annexin $\mathrm{A} 2$ was suspended in $20 \mathrm{mmol} / \mathrm{L}$ phosphate buffer $(\mathrm{pH}$ 7.5) (final concentration of $6.6 \mu \mathrm{g} / \mathrm{mL}$ ) and incubated with or without the purified $\operatorname{IgM}$ antibody $(0.02 \mu \mathrm{g} / \mu \mathrm{L})$ at $37^{\circ} \mathrm{C}$ for $30 \mathrm{~min}$. Prepared samples were then incubated with $\mathrm{N}$-terminal glutamic acid plasminogen $(0.1 \mu \mathrm{mol} / \mathrm{L}$; Carbiochem, Darmstadt, Germany) at $37^{\circ} \mathrm{C}$ for $1 \mathrm{~h}$ to form the annexin A2-plasminogen complex. Both t-PA $(0.01 \mu \mathrm{mol} / \mathrm{L}$; Technoclone, Vienna, Brunnerstr, Austria) and a fluorogenic plasmin substrate Boc-Val-Leu-LysMCA (125 $\mu \mathrm{mol} / \mathrm{L}$; Peptide Institute, Inc., Osaka, Japan) were added, and substrate hydrolysis was measured at 2-sec intervals as relative fluorescent units (RFU) with 380-nm excitation and 460-nm emission in a fluorescence spectrometer (FP-6500, Jasco, Tokyo, Japan).

Statistical analysis. Statistical analysis was performed using the software SPSS11.0 for Windows (SPSS Inc., Chicago, IL). First, we used the Pearson correlation and regression analysis to determine the association between anti-annexin A2 IgM titers and total serum IgM levels in patients with hyper-IgM. Second, we analyzed the distribution of anti-annexin A2 IgM titer for each group. Results were presented as medians and ranges. These distributions were compared using the Kruskal-Wallis test, followed by the MannWhitney nonparametric test. Third, in the plasmin generation inhibition assay, initial rates of plasmin generation were calculated using linear regression analysis of plots of RFU versus time ${ }^{2}$ and statistical analysis was conducted using a $t$ test. The study data are expressed as mean $\pm \mathrm{SD} ; p<0.05$ was considered significant.

\section{RESULTS}

Clinical features of 174 hyper-IgM patients. From 1981 to 2004, a total of 2433 VLBW infants $(40.0 \%$ of all admitted patients) were cared for in the neonatal intensive care unit (NICU) in Osaka Medical Center and Research Institute for Maternal and Child Health, Osaka, Japan, and 1966 (80.8\% of VLBW infants) sera from cord bloods were analyzed for their IgM levels. One hundred seventy-four patients (7.2\% of VLBW infants) had congenital hyper-IgM. Of these, only six proved to be infected with a specific pathogen by routine laboratory examinations; five were infected with cytomegalovirus infections and one with syphilis. One hundred forty-four placentas $(86.7 \%$ of patients with hyper-IgM on pathologic examination) showed CAM, and only 22 patients did not (Fig. 1).

Annexin A2 as a molecular target of IgM. By using Western blot, several proteins (three to nine per patient) were reacted with $\operatorname{IgM}$ from 12 hyper-IgM patients, and a $36-\mathrm{kD}$ protein was reacted frequently $(8 / 12,66.7 \%$; Fig. $2 A)$. In contrast, the protein was not detected in the age-matched control serum (0/4). It was detected in the membrane fraction of placenta and a cell line of human umbilical vascular endothelial cells (data not shown). Trypsin digestion of the 36-kD protein, followed by HPLC separation of the resulting peptides, gave rise to three major peaks whose N-terminal amino acid sequences were determined as TNQELQEINR, DLYDAGVK, LSLEGDXSTPPSAYGSVK, and AYTNFDAERDALNIETAIK. All these sequences were mapped to annexin A2 (NCBI Accession No. NP001002858).

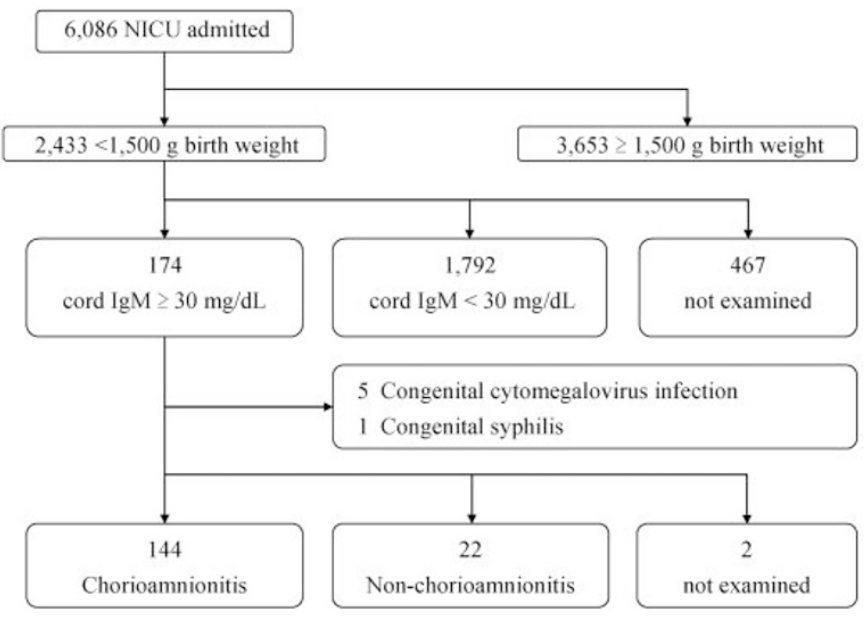

Figure 1. Incidence of hyper-IgM patients in Osaka Medical Center and Research Institute for Maternal and Child Health, Osaka, Japan, 1981-2004. 
To test the immunoreactivity of the patients' serum against annexin A2, we purified annexin A2 from the 100-K membrane fraction by immunoprecipitation with an anti-annexin A2 antibody. The immunoprecipitated annexin A2 was then used as an antigen source for Western blot detected by the patient's serum as a primary antibody, followed by antihuman IgM antibody detection. In contrast to the IgM reactivity to annexin A2, annexin A2 was not detected by antihuman IgG antibody as a secondary antibody (Fig. 2B).

Localization of annexin $A 2$ in placenta. To investigate the localization of annexin A2 in utero, the expression pattern in the placenta was examined by immunohistochemical staining. The expression of annexin A2 was observed in amniotic epithelial cells, chorionic trophoblasts, villous trophoblasts, and villous endothelial cells both in term and preterm placentas without CAM (Fig. 2C), which is consistent with a previous report (30). Furthermore, similar expression pattern was observed in CAM placentas (data not shown).

Anti-annexin A2 IgM titer. ELISA for annexin A2 was established to titrate the annexin A2 IgM antibody using the recombinant human annexin A2 (29). Thirty-four cord blood samples were collected from 1981 to 2004. The mean \pm SD of their IgM levels was $110.05 \pm 84.54 \mathrm{mg} / \mathrm{dL}$. Among the 34 patients with hyper-IgM, 20 (58.8\%) showed high titer (more than $\times 16$ ) against annexin $A 2$ in their cord blood. In contrast, in preterm infants without hyper-IgM $(n=5)$, term control infants $(n=12)$, and normal volunteer adults $(n=10)$ (the mean \pm SD of their IgM levels was $120.53 \pm 41.01 \mathrm{mg} / \mathrm{dL}$ ), the titer of anti-annexin A2 IgM antibody showed not more than $\times 16$ (Fig. 3).

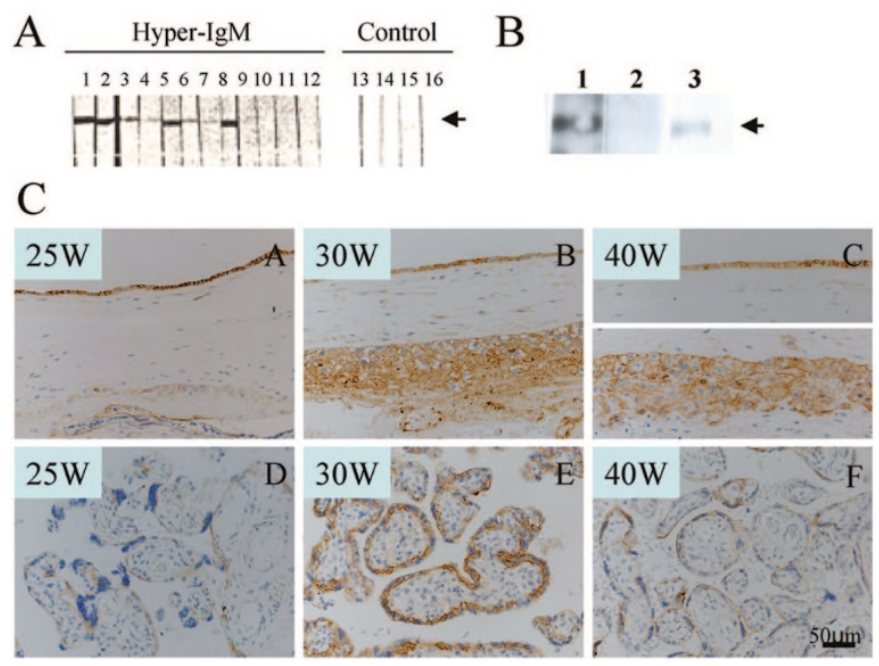

Figure 2. (A) IgM reacted with a $36-\mathrm{kD}$ protein in $66.7 \%(8 / 12)$ of patients with hyper-IgM. Lanes 1-12: cord blood sera from hyper-IgM patients; lanes 13-16: cord blood sera from normal term infants. $(B)$ IgM reacted with the immunoprecipitated annexin A2. Immunoprecipitation with serum from hyper-IgM patients (lanes 1 and 2) and anti-annexin A2 antibody (lane 3, positive control). Lane 1, second antibody, anti-human IgM antibody; lane 2, second antibody, anti-human $\operatorname{IgG}$ antibody. $(C)$ Annexin $\mathrm{A} 2$ was expressed in amniotic epithelial cells, chorionic trophoblasts, villous trophoblasts, and villous endothelial cells in term and preterm placentas. $(A-C)$ chorion and amnion; $(D, E)$ villi. The number at the top left corner indicates gestational age. Arrows indicate $36 \mathrm{kDa}(A, B)$.

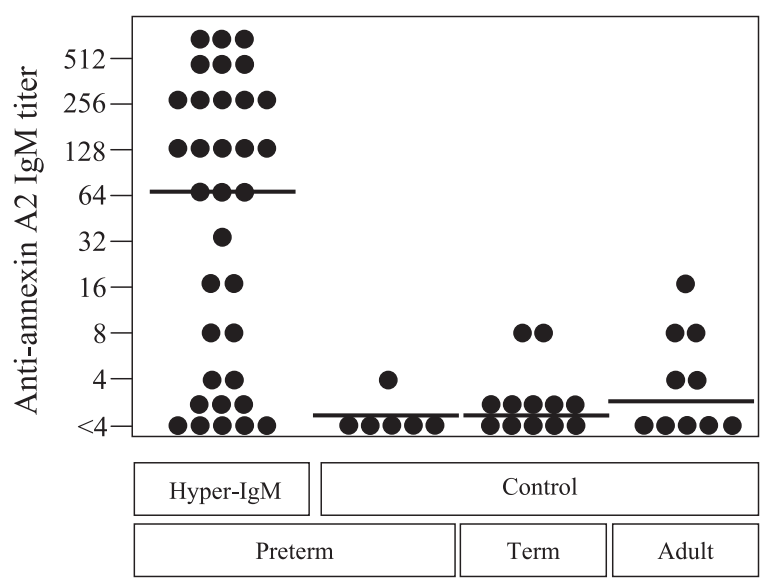

Figure 3. $58.8 \%$ (20/34) of hyper-IgM patients showed high titer (more than $\times 16)$ against annexin A2. Preterm gestational ages, $<37 \mathrm{wk}$. Term gestational ages, $\geq 37 \mathrm{wk}$. The short, bold, horizontal lines are the median for each group.

The association between the anti-annexin $\mathrm{A} 2 \operatorname{IgM}$ titer and total serum IgM level was examined. The anti-annexin A2 IgM titer did not correlate with the levels of serum $\operatorname{IgM}\left(R^{2}=\right.$ $0.041, p=0.253 ; n=34$ samples, Fig. $4 A$ ).

Proportion of anti-annexin A2 IgM antibody in total serum IgM. The proportion of annexin A2-specific IgM was measured by comparing the levels of IgM with and without absorption to recombinant annexin A2. The proportion of anti-annexin $\mathrm{A} 2 \mathrm{IgM}$ in total IgM ranged from $29.1 \%$ to $38.5 \%$ among four annexin A2 high-titer IgM samples (two samples showed $\times 256$ and two showed $\times 512)($ Fig. $4 B)$. On the other hand, the proportions of this IgM in three normal control adults were small $(0.0 \%-2.5 \%)$.

Anti-annexin A2 IgM functions as an inhibitor of plasmin generation. To explore the contribution of anti-annexin A2 IgM antibody to preterm infants with hyper-IgM, we tested whether purified IgM from anti-annexin A2 IgM high-titer patients inhibited plasmin generation. In Figure 5, patients'
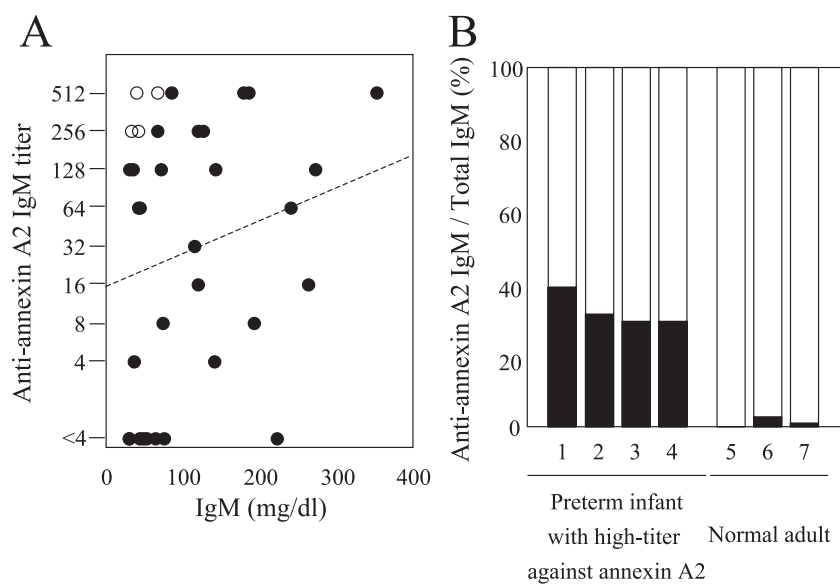

Figure 4. (A) The anti-annexin $\mathrm{A} 2 \mathrm{IgM}$ titer did not correlate with the levels of total IgM in patients with hyper-IgM. Open circles show patients who were examined the proportion of anti-annexin $\mathrm{A} 2 \operatorname{IgM}$ in total $\operatorname{IgM}\left(R^{2}=0.041 ; p\right.$ $=0.253)$. (B) The proportion of anti-annexin A2 IgM in total IgM; 1-4, preterm infants with high titer of anti-annexin $\mathrm{A} 2$ IgM antibody; (5-7, normal adults. 


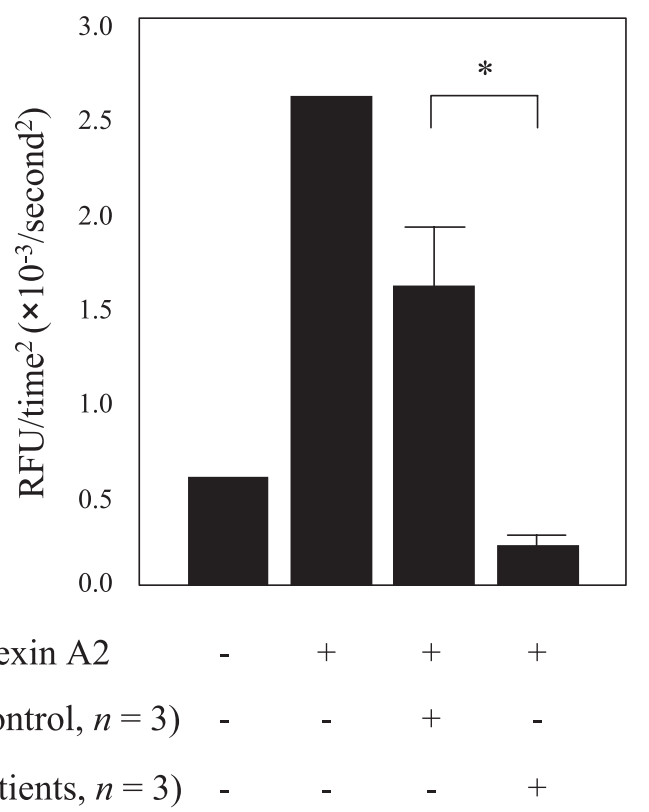

Figure 5. Patients' IgM inhibited the plasmin generation. vertical axis, initial rates of plasmin generation (RFU/time ${ }^{2}$ ). Control, IgM from normal human adults $(n=3)$. Patients, IgM from anti-annexin $\mathrm{A} 2 \mathrm{IgM}$ high-titer patients $(n=$ 3). $* p=0.001$.

IgM inhibited the plasmin generation more strongly compared with control $\operatorname{IgM}\left(1.58 \pm 0.26\right.$ versus $0.20 \pm 0.06 \mathrm{RFU} / \mathrm{min}^{2}$, $n=3, p=0.001$ ).

Relationship between the titer of anti-annexin A2 IgM antibody and CAM. To examine the correlation between the titer of anti-annexin A2 IgM antibody and CAM, we prospectively titrated anti-annexin A2 IgM antibody in preterm infants (gestational age $<37 \mathrm{wk}$ ) who were admitted to the NICU in and after 2005. A total of 37 cord blood specimens were available; all their placentas were pathologically classified. Their mean gestational age was $29.4 \pm 3.9 \mathrm{wk}$, and their mean birth weight was $1143.6 \pm 521.3 \mathrm{~g}$ (mean $\pm \mathrm{SD}$ ). In this study, first we divided subjects into three groups according to Blanc's classification; no CAM, low-grade CAM (grade I and II), and high-grade CAM (grade III). The median titers of anti-annexin A2 IgM antibody were $<4$ (range, $<4-16$ ) in patients without CAM, $<4$ (range, $<4-8$ ) in patients with low-grade CAM, and 4 (range, $<4-512$ ) in patients with high-grade CAM. The titer of anti-annexin A2 IgM antibody was significantly higher in patients with high-grade CAM than in patients without CAM $(p=0.011)$ and in patients with low-grade CAM $(p=0.010)$ (Fig. 6A). We classified nine high-grade CAM placentas into acute CAM $(n=5$; range, $<4-16)$ and subacute CAM $(n=4$; range, $<4-512)$. All three placentas from anti-annexin A2 IgM high-titer patients (more than $\times 16$ ) showed subacute grade III CAM, which was considered as persistent inflammation in the chorion and amnion (Fig. 6B).

\section{DISCUSSION}

Proinflammatory cytokines contribute to the morbidity of preterm infants. The inflammatory cascade is activated by the nuclear factor- $\kappa \mathrm{B}$ pathway of the innate immunity triggered by membrane Toll-like receptors $(31,32)$. On the other hand, little is known about the acquired immunologic response to pathogens and inflammation in preterm infants.

Pentameric IgM plays important roles in primary antigen trapping and complement activation (33). The level of IgM in cord blood is about one tenth that of the adult level, and elevation of IgM levels at birth is suggestive of intrauterine infection. Recent studies indicate the involvement of lowpathogenic microorganisms, such as Mycoplasma hominis, Ureaplasma urealyticum, Ureaplasma parvum, Gardnerella vaginalis (2), and oral pathogens (34), in intrauterine infections. However, only a small portion of newborns with hyperIgM show responsiveness to these microorganisms (35). Only $3.4 \%(6 / 174)$ of VLBW infants with hyper-IgM who were admitted to NICU from 1981 to 2004 were serologically diagnosed as having syphilis (one patient) and cytomegalovirus infection (five patients) (Fig. 1).

Early studies on infantile immunoglobulin synthesis showed that human neonatal B lymphocytes are capable of in vitro synthesis of autoantibodies, which are typically of the IgM class $(36,37)$. The above findings led us to investigate the autoimmunity, which may occur after microorganism clearance, in cord blood from preterm infants. We identified annexin A2, a host protein, as one of the target proteins of hyper-IgM in preterm infants at a high rate (Fig. 3). Our report is the first to demonstrate autoimmune fetal response in preterm infants associated with fetal inflammation.

ELISA titration for specific annexin A2 IgM antibody showed two groups: high titer and low titer (Fig. 3). We further analyzed the proportion of $\operatorname{IgM}$ in patients with a high titer of annexin A2 IgM antibody. This high-titer group revealed a high proportion of annexin A2 IgM in total serum IgM antibody ( $n=4$, about $20 \%-40 \%$, Fig. $4 B$ ). This result suggested the restricted divergence of IgM, although the statistical analysis of all analyzed patients between the titer of anti-annexin A2 IgM and the levels of total IgM did not show a significant correlation among all 34 patients with hyper-IgM (Fig. 4A). This result might be affected by the pathogenic microorganisms, the duration, and the severity of infection or inflammation.

Annexin A2 can function as a coreceptor for plasminogen and t-PA and acts as a positive modulator in the fibrinolytic
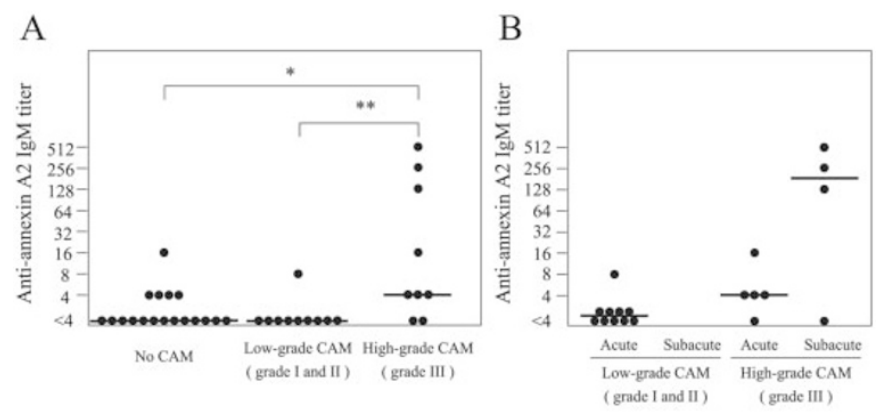

Figure 6. (A) The median titer of anti-annexin A2 IgM antibody was significantly higher in patients with high-grade CAM than in patients without CAM and in patients with low-grade CAM. $* p=0.011 ; * * p=0.010 .(B)$ Placentas from anti-annexin A2 IgM high-titer patients (more than $\times 16$ ) showed subacute grade III CAM. The short, bold, horizontal lines are the median for each group. 
cascade (22). This finding was consistent with our findings in anti-annexin A2 IgM high-titer patients (Fig. 5) and indicated that anti-annexin A2 IgM antibody functioned as a neutralization antibody in our study. However, there were no significant differences of fibrin deposition in the placenta between hightiter patients and low-titer patients at the optical microscope level (data not shown). Therefore, we prospectively analyzed the statistical significance between anti-annexin A2 IgM titer and CAM. We showed that the titer of anti-annexin A2 IgM antibody was significantly higher in patients with high-grade CAM than in patients without CAM and in patients with low-grade CAM (Fig. 6A). From this result, we speculate the titer of anti-annexin $\mathrm{A} 2 \mathrm{IgM}$ as a novel biomarker for the severity of CAM.

Anti-annexin A2 antibody was first demonstrated as an auto-IgM antibody in this study. A possible explanation for the production of this specific autoantibody was the localization, abundance, and immunogenic characteristic of annexin A2. Immunohistochemical analysis showed that annexin A2 is expressed at the fetal membrane of amnion, chorion, and endothelial cells, especially in amnion (Fig. 2C). According to Blanc's classification, grade III (high-grade) CAM is defined by the infiltration of the inflammatory cells from chorion to amnion. Moreover, all three placentas from anti-annexin A2 IgM high-titer patients showed subacute grade III CAM, which is persistent inflammation in the chorion and amnion (Fig. 6B). From these observations, we speculate the mechanism of annexin A2 IgM production as follows. First, amnion was destroyed by infiltrated inflammatory cells. Annexin A2 was released from the membrane, which led to the production of specific IgM. However, we have no evidence for the hyperimmunogenic character of annexin A2. Another explanation for anti-annexin $\mathrm{A} 2 \mathrm{IgM}$ production is the immaturity of the B-cell function in the preterm infants. It has been reported that the $\mathrm{V}_{\mathrm{H}} \mathrm{D}_{\mathrm{H}} \mathrm{J}_{\mathrm{H}}$ diversity in IgM transcripts in cord blood from preterm infants (gestational age, 25-29 wk) shows about $80 \%$ compared with the term neonates. The diversity of the $\mathrm{V}_{\mathrm{H}}$ region gene repertoire is developmentally controlled and independent of environmental influences. Further, $48 \%$ of the cord blood from preterm infants had no $\mathrm{N}$ nucleotides between $\mathrm{D}_{\mathrm{H}}$ and $\mathrm{J}_{\mathrm{H}}$, indicating that fewer DNA rearrangements were observed in preterm infants (38). This previous report may support our data of the high proportion of the specific antibody against annexin A2 in four high-titer preterm infants.

In summary, we identified annexin A2 as the target of IgM antibody in preterm infants. This is a first report about the autoimmune $\operatorname{IgM}$ antibody produced by preterm infants at the local area of the fetomaternal interface. The patients' IgM inhibited plasmin generation. The titer of this anti-annexin A2 IgM antibody might be able to function as the marker of highgrade CAM, i.e. FIRS. Further studies are needed to clarify the participation of this IgM antibody in developing CAM.

\section{REFERENCES}

1. Goldenberg RL, Rouse DJ 1998 Prevention of preterm birth. N Engl J Med 339:313-320
2. Goldenberg RL, Hauth JC, Andrews WW 2000 Intrauterine infection and preterm delivery. N Engl J Med 342:1500-1507

3. Romero R, Chaiworapongsa T, Kuivaniemi H, Tromp G 2004 Bacterial vaginosis, the inflammatory response and the risk of preterm birth: a role for genetic epidemiology in the prevention of preterm birth. Am J Obstet Gynecol 190: 1509-1519

4. Fredricks DN, Fiedler TL, Marrazzo JM 2005 Molecular identification of bacteria associated with bacterial vaginosis. N Engl J Med 353:1899-1911

5. Kitajima H, Nakayama M, Miyano A, Shimizu A, Taniguchi T, Shimoya K, Matsuzaki N, Fujimura M 1992 Significance of chorioamnionitis. Early Hum Dev 29:125-130

6. Hallman M 1999 Cytokines, pulmonary surfactant and consequences of intrauterine infection. Biol Neonate 76:2-9

7. Goepfert AR, Andrews WW, Carlo W, Ramsey PS, Cliver SP, Goldenberg RL, Hauth JC 2004 Umbilical cord plasma interleukin-6 concentrations in preterm infants and risk of neonatal morbidity. Am J Obstet Gynecol 191:1375-1381

8. Gomez R, Romero R, Ghezzi F, Yoon BH, Mazor M, Berry SM 1998 The fetal inflammatory response syndrome. Am J Obstet Gynecol 179:194-202

9. Northway WH Jr, Rosan RC, Porter DY 1967 Pulmonary disease following respirator therapy of hyaline-membrane disease. Bronchopulmonary dysplasia. N Engl J Med 276:357-368

10. Wilson MG, Mikity VG 1960 A new form of respiratory disease in premature infants. Am J Dis Child 99:489-499

11. Fujimura M, Takeuchi T, Ando M, Funato M, Shimada S, Tsujimoto A, Kanaya S, Kozuki K, Morinoto S 1983 Elevated immunoglobulin M levels in low birth weight neonates with chronic respiratory insufficiency. Early Hum Dev 9:27-32

12. Fujimura M, Takeuchi T, Kitajima H, Nakayama M 1989 Chorioamnionitis and serum IgM in Wilson-Mikity syndrome. Arch Dis Child 64:1379-1383

13. Gerke V, Moss SE 2002 Annexins: from structure to function. Physiol Rev 82:331371

14. Ma G, Greenwell-Wild T, Lei K, Jin W, Swisher J, Hardegen N, Wild CT, Wahl SM 2004 Secretory leukocyte protease inhibitor binds to annexin II, a cofactor for macrophage HIV-1 infection. J Exp Med 200:1337-1346

15. Raynor CM, Wright JF, Waisman DM, Pryzdial EL 1999 Annexin II enhances cytomegalovirus binding and fusion to phospholipids membranes. Biochemistry 38:5089-5095

16. Malhotra R, Ward M, Bright H, Priest R, Foster MR, Hurle M, Blair E, Bird M 2003 Isolation and characterisation of potential respiratory syncytial virus receptor(s) on epithelial cells. Microbes Infect 5:123-133

17. Mosleh IM, Huber LA, Steinlein P, Pasquali C, Gunther D, Meyer TF 1998 Neisseria gonorrhoeae porin modulates phagosome maturation. J Biol Chem 273:35332-35338

18. Merrifield CJ, Rescher U, Almers W, Proust J, Gerke V, Sechi AS, Moss SE 2001 Annexin 2 has an essential role in actin-based macropinocytic rocketing. Curr Biol 11:1136-1141

19. Fan X, Krahling S, Smith D, Williamson P, Schlegel RA 2004 Macrophage surface expression of annexins I and II in the phagocytosis of apoptotic lymphocytes. Mol Biol Cell 15:2863-2872

20. Knop M, Aareskjold E, Bode G, Gerke V 2004 Rab3D and annexin A2 play a role in regulated secretion of $\mathrm{vWF}$, but not tPA, from endothelial cells. EMBO J 23:2982-2992

21. Ling Q, Jacovina AT, Deora A, Febbraio M, Simantov R, Silverstein RL, Hempstead B, Mark WH, Hajjar KA 2004 Annexin II regulates fibrin homeostasis and neoangiogenesis in vivo. J Clin Invest 113:38-48

22. Cesarman GM, Guevara CA, Hajjar KA 1994 An endothelial cell receptor for plasminogen/tissue plasminogen activator (t-PA). II. Annexin II-mediated enhancement of t-PA-dependent plasminogen activation. J Biol Chem 269:2119821203

23. Menell JS, Cesarman GM, Jacovina AT, McLaughlin MA, Lev EA, Hajjar KA 1999 Annexin II and bleeding in acute promyelocytic leukemia. N Engl J Med 340:9941004

24. Brichory FM, Misek DE, Yim AM, Krause MC, Giordano TJ, Beer DG, Hanash SM 2001 An immune response manifested by the common occurrence of annexins I and II autoantibodies and high circulating levels of IL-6 in lung cancer. Proc Natl Acad Sci U S A 98:9824-9829

25. Rand JH 2000 The annexinopathies: a new category of diseases. Biochim Biophys Acta 1498:169-173

26. Blanc WA 1981 Pathology of the placenta, membranes and umbilical cord in bacterial, fungal and viral infections in man. Monogr Pathol 22:67-132

27. Miyano A, Miyamichi T, Nakayama M, Kitajima H, Shimizu A 1998 Differences among acute, subacute, and chronic chorioamnionitis based on levels of inflammation-associated proteins in cord blood. Pediatr Dev Pathol 1:513-521

28. Hajjar KA, Hamel NM 1990 Identification and characterization of human endothelial cell membrane binding sites for tissue plasminogen activator and urokinase. J Biol Chem 265:2908-2916

29. Tabata A, Namba F, Yamada M, Hasegawa T, Nakahira K, Hamada D, Kitajima H, Fukusaki E, Yamagihara I 2006 Expression and purification of recombinant human annexin A2 in Pichia pastoris and the utility of the expression product for detecting annexin A2 antibody. J Biosci Bioeng 101:190-197

30. Sun M, Liu Y, Gibb W 1996 Distribution of annexin I and II in term human fetal membranes, decidua and placenta. Placenta 17:181-184

31. Dembinski J, Martini R, Behrendt D, Bartmann P 2004 Modification of cord blood IL-6 production with IgM enriched human immunoglobulin in term and preterm infants. Cytokine 26:25-29 
32. Akira S, Takeda K 2004 Toll-like receptor signaling. Nat Rev Immunol 4:499-511

33. Youd ME, Ferguson AR, Corley RB 2002 Synergistic roles of IgM and complement in antigen trapping and follicular localization. Eur J Immunol 32:2328-2337

34. Boggess KA, Moss K, Murtha A, Offenbacher S, Beck JD 2006 Antepartum vaginal bleeding, fetal exposure to oral pathogens, and risk for preterm birth at $<35$ weeks of gestation. Am J Obstet Gynecol 194:954-960

35. Aho K, Palosuo T, Andersson M, Turunen H, Terho P, Vesikari T, Leinikki P 1987 Raised acute-phase glycoprotein and IgM levels in cord serum. Gynecol Obstet Invest 24:50-55
36. Pisetsky DS, Jelinek DF, McAnally LM, Reich CF, Lipsky PE 1990 In vitro autoantibody production by normal adult and cord blood B cells. J Clin Invest 85:899-903

37. Ailus K, Palosuo T 1995 IgM class autoantibodies in human cord serum. J Reprod Immunol 29:61-67

38. Bauer K, Zemlin M, Hummel M, Pfeiffer S, Karstaedt J, Steinhauser G, Xiao X, Versmold H, Berek C 2002 Diversification of Ig heavy chain genes in human preterm neonates prematurely exposed to environmental antigens. J Immunol 169:1349-1356 